\title{
BALNEOTERAPIA DO PACIENTE QUEIMADO SISTEMATIZAÇÃO DO ATENDIMENTO DE ENFERMAGEM
}

\author{
Arlete Oguisso da Cruz * \\ Lourdes Muller *
}

RBEn/10

CRUZ, A.O. e MULLER, L. - Balneoterapia do paciente queimado. Sistematização do atendimento de enfermagem. Rev. Bras. Ene.; DF, $29: 87-90,1976$.

\section{Considerações Cerais}

O tratamento de quelmados apresenta paculiaridades próprias que exígem a instalação de unidades especiais, visando não só uma rápida recuperação, como também a prevenção de sequelas. Para facilitar 0 atendimento de emergência, dentro dos padrões técnicos recomendados, a área de internação para pacientes queimados deve estar localizada, de preferência, junto à unidade de emergência (PS) e ser de fácil acesso e ao abrigo de poeiras e ruidos.

O ideal seria adotar um sistema de isolamento, a fim de controlar a infecção proveniente do próprio paciente.

Entretanto, dado o alto índice de permanência hospitalar, em média 53 dias de internação (Unidade de Queimados do Hospital das Clínicas de São Paulo em 1974), do ponto de vista psicológico é desaconselhável. A internação atual em enfermarias de 8 a 12 leitos favorece a comunicaça entre os pacientes, facilita a observação e o trabalho da equípe de enfermagem, principalmente ẹm se tratando de crianças.

Considerando que a infecgāo das lesbes constitui o maior problema no tratamento de queimados, é importante lembrar que as medidas de controle de contaminação do meio ambiente, devem ser adotadas e seguidas com rigor. Entre os setores de uma unidade de queimados, a balneoterapla ocupa um lugar de destaque.

Portanto, o presente trabalho visa, despretensiosamente, oferecer subsidios para a instalação e funcionamento de um setor de balneoterapia.

A hidroterapia no paciente queimado remonta a séculos passados, quando pesquisadores imergiam seus doentes em água pura (hipotônica), ou nas mals variadas soluções frias ou quentes, com a finalidade de remover toxinas da área cruenta e facilitar a cicatrização. Entre nós, o professor Ary do Carmo Russo, em 1945, aconselhava a imersão dos pacientes quelmados em égua sallns na temperatura de $38 .^{\circ} \mathrm{C}$, duas ou três vezes por semana com o objetivo de limpar a área queimada.

Em 1946, seguindo a orientação preconizada por Carrel de Relly, em 1917, passou a recomendar a utillsaçăo de compressas úmidas, com solução de

- Enfermeiras do Fospital das Cilnicas da USP. 
CRUZ, A.O. e MULLER, L. - Balneoterapia do paciente queimado. Sistematizaçāo do atendimento de enfermagem. Rev. Bras. Enf.; DF, 29 : 87-90, 1976.

Dakin a $1 \%$ ou antibiótico (penicilina) ou ainda antisséptico como mertiolate no banho.

A partir de 1959, o Hospital das Clínicas da USP, passou a utilizar, para pacientes queimados, a técnica de banho de imersão em solução salina a $0,09 \%$ na temperatura desejada pelo paciente (em geral, em torno de $40^{\circ} \mathrm{C}$ ).

A solução salina a $0,09 \%$ (solução isotônica), semelhante ao humor do organismo, visa evitar a desidratação ou absorção de líquido através das lesões. A compressa úmida, com solução de Dakin a $50 \% 1 / 3$ e Soro-Fisiológico a $2 / 3$, também tem sido utilizada para pacientes em estado grave e com área de necrose úmida ou para doentes cuja extensão da lesão não justifica o banho completo. A compressa é molhada com a solução acima mencionada cada 2 horas.

\section{Finalidades}

A balneoterapia é um excelente recurso técnico, como tratamento de pacientes queimados, por ocasião da troca de curativos, ou limpeza da área cruenta para enxertia.

Pode-se destacar três finalidades principais:

- Higiênica - evitar a infecção, por meio da remoção de impurezas e da manutenção da área cruenta limpa.

- terapêutica - facilitar a cicatrização, graças à melhoria das condições de circulação sanguínea;

- preventiva - prevenir sequelas de retração cicatricial, através dos exercícios ativos realizados pelo paciente, livre de ataduras e imerso em solução.

Entretanto, existe a possibilidade de uma ação secundária e indesejável, que deve ser controlada, principalmente em paciente com área cruenta extensa ou no primeiro banho, para evitar:
- Hemorragia capilar - por dilatação dos vasos sanguíneos;

- lipotímia - por vasodilatação e perda de líquido sero-sanguinolento, através de lesōes;

- maceração e aprofundamento das lesões por excesso de banho, em geral banhos diários;

- contaminação de área não infectada, transmitida pela solução que está em contato com a área infectada.

\section{III - Instalação - equipamento - Instrumental}

A sala para balneoterapia deverá situar-se junto à sala de curativos e obedecer aos princípios técnicos de prevenção de infecção, semelhantes aos do centro cirúrgico.

Com dimensões aproximadas de $12 \mathrm{~m}^{2}$ paredes e piso de material de fácil límpeza, forro pintado com tinta não impermeabilizante, para suportar a ação do calor úmido, janelas amplas com telas micrometradas para evitar a penetração de insetos, possibilitar a lluminação e aeração natural e permitir a eliminação do vapor. Equipada com: banheira colocada a $70 \mathrm{~cm}$ do piso, para facilitar a movimentação do paciente e do pessoal de enfermagem, tendo régua para medir a altura da água e termômetro para temperatura; mesa auxiliar de material inoxidável; armário ou prateleira de madeira ou material inoxidável, balança, tipo caseiro, para pesar o sal; recipiente de plástico para lixo; recipiente de plástico ou de vidro com sal, pacotes de curativo; gorro e máscara, de preferência descartáveis, pacotes de gase, luvas, aventais e campos grandes e médios; 1 tesoura de Lister; revestimento plástico para banheira.

\section{IV - Pessoal}

0 tratamento de queimados exige uma equipe especializada, e principalmente no tocante à enfermagem que diuturna- 
CRUZ, A.O. e MULWFR, L. - Balneoterapla do paciente queimado. Sistematizaçăo do atendimento de enfermagem. Rev. Bras. Enf.; DF, 29 : 87-80, 1976.

mente se presta a cuidados diretos ao paciente. A enfermelra como líder da equipe de enfermagem é a mais indicada para programar e executar o banho terapêutico.

Contudo, o auxiliar de enfermagem, devidamente treinado e supervisionado pela enfermeira, poderá executar esta técnica.

\section{V - Sistematização da Balneoterapia}

Recomenda-se a balneoterapia para pacientes com área cruenta, a freqüência do banho é de três. vezes por semana, com duração de aproximadamente $40 \mathrm{mi}$ nutos.

\section{Preparo da sala de banho:}

- lavar a banheira com água, sabão e solução de hipocloreto de sódio a $3 \%$;

- forrar a banheira com plástico próprio (plástico fino com a forma da banheira e rebordo que permita forração total);

- abrir a torneira de água quente (mais ou menos 40. ${ }^{\circ}$ ), e deixar encher a banheira até 150 litros (a água é proveniente da caldeira);

- pesar o sal na proporção de $0,09 \%$ (exemplo: 1.350 gramas de sal por 150 litros de água);

- colocar o material a ser usado na mesa auxillar.

2. Preparo do paciente:

- orientar o paciente quanto à técnica da balneoterapia e suas finalidades;

- verificar se os cabelos, as mãos e os pés estão limpos, caso contrário dar antes o banho no leito;

- observar se as unhas estão aparadas e se fol feita a tricotomia axilar e pubiana (a tricotomia deverá ser feita semanalmente);
- controlar os sinais vitais e registrá-los;

- conduzir o paciente à sala de banho;

- retirar os curativos não aderentes, cortando as ataduras com tesoura;

- colocar o paciente na banheira, imergindo as regiōes cruentas.

3. Preparo do executante:

- lavar as mãos, escovando-as;

- vestir gorro, avental e máscara esterilizados:

- calçar luvas esterilizadas.

4. Técnica do banho terapêutico:

- deixar o paciente Imerso na solução durante mais ou menos $10 \mathrm{mi}$ nutos, fazendo movimentação ativa ou passiva da musculatura da região atíngida pela queimadura;

- observar sintomas de efeitos secundários e preveni-los;

- retirar os curativos aderentes, depols de descolado pela solução;

- lavar as lesões com sabão de glicerina, usando pinça e gase para remover os detritos de pele e impurezas acumuladas;

- retirar o paciente da banheira e envolvê-lo em campo esterilizado e transportá-lo para a sala de curativos;

- observar e anotar o aspecto das lesões.

Na sala de curativos, prosseguir o tratamento de acordo com as lesões, completando o curativo com ou sem a oclusão das mesmas.

\section{Cronometragem da técnica de} balneoterapia

Durante 3 meses fol realizada na Un1dade de Queimados do Hospital das Clinicas, uma cronometragem da técnica de banho terapêutico executado por uma 
CRUZ, A.O. e MULWFR, L. - Balneoterapla do paciente queimado. Sistematizaçāo do atendimento de enfermagem. Ret. Bras. Enf.; DF, 29 : 87-90, 1976.

auxillar de enfermagem, com os seguintes resultados:

- para o preparo da sala de banho e do paciente, em média 18 minutos;

- para o banho terapéutico, em média 45 minutos, sendo que o tempo minimo observado, para casos de lesões menos extensas fol de 16 minutos, e tempo máximo, para pacientes com lesões extensas fol de $60 \mathrm{mi}-$ nutos;

- para os demais tempos do curativo, executado na sala apropriada, tempo médio 16 minutos.
- Total para a balneoterapia completa: em média 79 minutos ou sejam 1 hora e 20 minutos.

A balneoterapia sendo um recurso técnico usado há séculos, reveste-se hoje de cuidados especiais, principalmente no tocante ao controle de infecçōes cruzadas e efeitas secundários. Portanto, é necessário contar com uma equipe de enfermagem devidamente treinada para poder atingir seus objetivos fundamentais.

\section{BIBLIOGRAFIA}

ALBUQUERQUE, A. - O banho salino no tratamento das queimaduras. R.P.H. $22(8): 421-129,1874$.

RUSSO, A.C. - Queimaduras. Ivraria
Luso-Wspanhola e Brasileira, Sāo Paulo, 1969.

SANa8, R. - Cuidados tópicos nos grandes queimados. J.B.M. 20 (4) : 55-78, 1971 